\title{
Las redes de políticas como herramientas de análisis. Notas a partir de intervenciones recientes en materia de desarrollo rural en Argentina (2008-2014)
}

\author{
María Elena NogUeIRA* \\ Universidad Nacional de Rosario \\ mariaelenanogueira@gmail.com
}

Recibido: 28/04/2015

Aceptado: 23/05/2015

\begin{abstract}
Resumen
Las redes de políticas (policy networks) llevan ya algunos años en la agenda de conceptos de la Ciencia Política. La posibilidad de observar de un modo crítico las relaciones inter-gubernamentales en diferentes niveles, identificando actores y acciones en contextos diversos resulta una herramienta de gran interés analítico. En este trabajo, se propone un recorrido por parte de la literatura sobre las redes de políticas para dar cuenta de aquellas existentes en materia de políticas de desarrollo rural en Argentina en el último tiempo. El artículo se compone de una Introducción; un segundo apartado en el que se presentan los aspectos teóricos vinculados con el Estado, las políticas públicas y las redes; un tercer apartado señalando algunas características de las intervenciones en materia de desarrollo rural en el país y un cuarto, dedicado al análisis de algunas experiencias en red. Finalmente, se presentan conclusiones que enfatizan el rol protagónico del Estado en las redes y, asimismo, las difícultades y desafíos que presentan estos espacios intermedios en la relación sistema político/ sociedad en cuanto aparecen, la mayoría de las veces, como redes «en el papel».
\end{abstract}

Palabras clave: redes de políticas, desarrollo rural, Argentina.

\section{Policy networks as tools of analysis. Notes from recent interventions on rural development in Argentina (2008-2014)}

\begin{abstract}
Policy networks already have been part of the in Political Science for many years. The ability to look critically inter-governmental relationships at different levels in order to identify actors and actions in several contexts is a tool of great analytical value. In this paper, a route is proposed by the literature on policy networks to account for those existing in the field of rural development policies in Argentina in recent times. This paper presents an introduction, after that, a second section in which theoretical aspects connected with the State, public policies and networks are developed; a third paragraph indicates some characteristics of interventions in rural development in the country and, a fourth section is dedicated to analyze a number of experiences. Finally, some conclusions emphasize the leading role of the State in policy network and also the difficulties and challenges that these have as in-between the relationship political system /society in which they are present, most of the time, as networks «on paper».
\end{abstract}

Key words: policy network, rural development, Argentina.

* La autora agradece mucho a los árbitros cuyas evaluaciones fueron muy importantes en cuanto a los aportes para mejorar el escrito y la investigación en general. 


\section{Introducción}

Desde siempre, Argentina ha sido un país muy vinculado con el sector agropecuario, no sólo en términos económicos -en cuanto este sector ha sido el principal proveedor de divisas a lo largo del tiempo-, sino también por el peso que ha tenido, no ya estrictamente lo sectorial sino más bien «lo rural», aquello vinculado con el «el campo», en la formación de la cultura, las relaciones sociales y la vida en sociedad.

Un autor como Bengoa (2003) describe y analiza los grandes desplazamientos que «lo rural» ha tenido en los últimos treinta años señalando la pérdida de autonomía que se manifiesta tanto en términos de espacio social, como productivo y cultural, aquello que suele denominarse «sociedad rural». Evidencia de esto puede encontrarse, en términos más empíricos, en la enorme cantidad de programas y líneas de desarrollo rural que en los últimos veinte años se han diseminado por América Latina y Argentina en particular, desde una perspectiva territorial, comprendiendo lo rural en un sentido amplio: las tradicionales actividades agrícolo-ganaderas, la producción de servicios, la confección y elaboración de distintos tipos de artesanías, la pesca, el turismo rural, entre otros. En este contexto los programas y políticas orientados al desarrollo rural van nutriéndose de estas transformaciones que también tienen efectos en los sujetos del desarrollo rural, fundamentalmente un heterogéneo conjunto de agricultores familiares y los actores colectivos diversos que también participan de los programas.

Dada esta complejidad, interesa poder analizar un aspecto de la historia más reciente de las políticas de desarrollo rural desde la perspectiva de las redes de políticas públicas, identificando actores y tipos de vínculos para el caso propuesto. Para este trabajo, se tomarán en cuenta dos tipos de actores: aquellos vinculados con el Estado, a través de los espacios (agencias y ámbitos formales de discusión) que han existido o existen para la gestión del desarrollo rural (no del sector agropecuario en forma general) y, de la sociedad civil, a través del Foro de la Agricultura Familiar (FoNAF) en términos amplios. Asimismo, la mención a los programas de desarrollo rural será en términos de instrumentos de política pública. A partir de esta identificación se pretende indagar en la forma de vinculación de espacios estatales y actores de la sociedad civil a través de algunas experiencias concretas. Con este propósito, el texto se divide en cuatro apartados, el último de ellos dedicado a conclusiones preliminares.

Luego de esta Introducción, se presentan los principales elementos teóricos para el análisis. Por un lado, se describen los conceptos que guían el trabajo ${ }^{1}$, y por otro, se plantea una breve revisión literaria sobre la temática de las redes y su utilidad, señalando el concepto que se tomará para el análisis. En el apartado tercero, se elabora una muy breve historia de las intervenciones en materia de desarrollo rural en el país, marcando sus grandes líneas de acción, contextos e instrumentos. Por su parte, en el cuarto apartado, se analizan cuatro experiencias a priori presentadas como espacios para

${ }^{1}$ Este artículo se enmarca en el plan de trabajo anual de la carrera de investigador científico del Consejo Nacional de Investigaciones Científicas y Técnicas (CONICET)-Argentina, titulado «Las redes de políticas como herramientas de gestión. Elementos para un análisis de la política de desarrollo rural para la agricultura familiar (2009-2014)». 
redes. Interesa particularmente dar cuenta del rol del Estado, a través de sus agencias, programas y funcionarios, en dichas redes y sus alcances. En el último apartado, se señalan algunas conclusiones preliminares, advirtiendo, en especial, las grandes dificultades que acontecen en materia de gestión pública, estatal, para trascender la lógica de la red sólo en «el papel».

Finalmente, se indica que para la realización de este trabajo se utilizó un conjunto de técnicas de recolección y análisis de datos de carácter cualitativo, en la medida que, en términos de Kreimer y Thomas (2007), se trata de un ejercicio de comprensión e interpretación de los significados intersubjetivos de acciones sociales. Con este fin se utilizaron dos tipos de técnicas: a) observación de datos y documentos y b) entrevistas en profundidad y estructuradas. En relación con a) se realizó un análisis de fuentes primarias, entendiéndolas como archivos, registros, actas y documentación que dan cuenta del objeto propuesto para el período señalado (Kreimer y Thomas, 2007) ${ }^{2}$. En términos de b) se realizaron entrevistas en profundidad a funcionarios y académicos involucrados en la gestión de los programas considerados a tales fines, informantes calificados. Para el análisis de las entrevistas se utilizó el programa Atlas.ti. Se trata de un software que asiste al investigador que utiliza una estrategia cualitativa, en el análisis de distintos tipos de recursos: textos, fotografías e imágenes, etc. Es una herramienta que permite el almacenamiento de datos y su codificación a través de conceptos clave en la investigación, de allí su gran utilidad. El programa, en este caso a partir del análisis de entrevistas, permitió la categorización de la información de acuerdo a los objetivos, y la codificación y estructuración de los aspectos conceptuales relevantes desde la perspectiva teórica propuesta. Es importante señalar que el programa utiliza como fundamento teórico la teoría fundada en los datos (Grounded Theory) de Glaser y Strauss (1997), cuyo énfasis está puesto en las interpretaciones de lo subjetivo a través de las propias interpretaciones de los sujetos (San Martín Cantero, 2014).

\section{Aspectos conceptuales}

\subsection{Sobre el Estado y las políticas públicas}

En términos generales, es posible señalar algunos matices en materia de la relación del Estado con la sociedad, y más especialmente, del Estado con la administración pública y la sociedad, que han afectado los modos de elaboración de las políticas públicas (comprendidas éstas, en términos analíticos, a partir de diferentes fases ${ }^{3}$ ). En palabras

2 En particular, se trabajó con 1) documentos, sistematizaciones, minutas y resoluciones varias, manuales operativos de los programas de carácter oficial 2) resoluciones ministeriales y leyes, y 3) prensa gráfica.

3 Lahera Parada (2002) señala que, en materia de políticas públicas se pueden distinguir cuatro momentos analíticos (no necesariamente consecutivos): origen, diseño, gestión y evaluación. De este modo, «el ciclo analítico refleja un modelo de aprendizaje continuo» (Lahera Parada, 2002:75). El autor advierte que «las políticas rara vez se extinguen por completo; es más habitual que cambien o se combinen con otras» (Lahera Parada, 2002:74).. Se volverá a la noción de «ciclo» más adelante. 
de Aguilar Villanueva (2006), esto se vincula con un problema político esencial: el pasaje del «sujeto» al «proceso» de gobierno. Si bien este autor centra su análisis sobre el gobierno, es preciso dar cuenta de las características que los Estados asumen en términos de los gobiernos ${ }^{4}$. En este punto debe destacarse que «formular e implementar políticas es la esencia de la actividad del Estado» (Oszlak, 1984:15). Sólo para dar cuenta de la posición sobre este complejo institucional, se tomará aquí la definición, de raíz weberiana, de O'Donnell (2010), al decir que se trata de un complejo institucional moderno que se relaciona de maneras diversas con la sociedad civil, condensando su poder y «devolviendo» acciones a través de las políticas públicas. Este autor manifestó un particular interés en las «mediaciones» (O'Donnell, 1978) o «puntos de encuentro» (O'Donnell, 2003 y 2010) del Estado con la sociedad civil. Hacia fines de la década de 1970, señalaba al Estado como «el componente específicamente político de la dominación en una sociedad territorialmente delimitada» (O'Donnell, 1978:1172). Siendo el Estado un aspecto de las relaciones sociales en el capitalismo, O`Donnell utiliza el término «fetichización», objetivación, del Estado para dar cuenta de una de las formas en la que se manifiestan las instituciones estatales: la administración burocrática que hace a la organización general del Estado, desde sus aspectos más vinculados con el «día a día» (rutina). Al respecto, las administraciones burocráticas son aquellas que ponen en práctica una «repetición natural» cuya contribución fundamental es el «Estado objetivado en burocracia» (O'Donnell, 1978:1176). Desde este punto de vista, la administración pública, constituida como un punto de encuentro en una concepción del Estado que trasciende su descripción en términos del aparato, se ubica en el contexto de las relaciones de dominación, estableciéndose allí como una institución estatal de carácter burocrática. Años después, en un contexto diferente, el autor señala esta mediación o «punto intermedio» como uno aspecto relevante para considerar la calidad de los regímenes democráticos (O’Donnell, 2010).

Es conocido el hecho que, tras las crisis de los denominados Estados de Bienestar, sobrevino un diagnóstico de carácter conservador. En este sentido, Portantiero (1989) señala en forma crítica el planteo de la denominada Comisión Trilateral ${ }^{5}$ en la década

${ }^{4}$ En este escrito, el término gobierno se utilizará, siguiendo a Levi (1998) como un aspecto del Estado, en cuanto se constituye como un «conjunto de órganos a los que institucionalmente les está confiado el ejercicio del poder» (Levi, 1998: 710). Sin embargo, O'Donnell (2010), entiende por gobierno a «las posiciones en la cúpula de las instituciones del Estado a las que se accede a través del régimen y permiten a los respectivos funcionarios tomar o autorizar (...) decisiones normalmente emitidas como reglas legales obligatorias sobre la población y el territorio delimitado por el Estado» (O`Donnell, 2010: 82). Camou, lo define de un modo similar: «conjunto de órganos y personas a las que institucionalmente les está confiado el ejercicio del poder estatal, o dicho de otra manera la toma de decisiones jurídicamente vinculantes» (2001:28). Se considera que, a los fines analíticos, resulta más pertinente establecer el análisis en el plano del Estado, considerando en todo caso, al gobierno como un «aspecto» del Estado. No obstante, las decisiones del gobierno en los términos de O'Donnell y Camou, serán tenidas en cuenta para el análisis de las experiencias propuestas.

${ }^{5}$ El texto que es tomado como referencia de la Comisión Trilateral es el de Michel Crozier, Samuel Huntington y Joji Watanuki (1975), The crisis of Democracy. Report on the governability of the democracies to the Trilateral Comission, New York University Press. Disponible en http://www.trilateral.org/ download/doc/crisis_of_democracy.pdf. Consultado el 07/05/2015. 
de 1970, que impulsaba la mercantilización de las prestaciones sociales y la necesidad de «despolitizar» la sociedad, con el fin de no «cargar» al Estado con un exceso de demandas. Los gobiernos de Thatcher en Inglaterra y Reagan en Estados Unidos valen como muestra cabal de estos postulados. En este contexto, y siguiendo a Camou (2001: 10), la «gobernabilidad» resultó puesta en duda de cara al agotamiento del Estado interventor, la crisis socio-económica y el «cambiante itinerario de las transiciones y consolidaciones democráticas». La cuestión de la gobernabilidad se introduce más actualmente con matices importantes que la alejan de la posición trilateral. Se volverá a esta cuestión en el siguiente apartado.

Luego de las reformas estatales denominadas de «primera» y «segunda» generación entre finales de 1980 y 2000, el Estado y la administración pública se han modificado. Oszlak (1999) señala dos «modelos» de reforma. Las de «primera generación» muestran como registro más evidente la afirmación «menos Estado». Esto, no significa -«achicarse»- en términos del aparato sino que «ese aparato [el existente] desarrollaba funciones y actividades que en el nuevo contexto ideológico pasaron a ser considerados ilegítimos» (Oszlak, 1999:4). La segunda reforma, por el contrario, supone alcanzar la «racionalidad organizativa y funcional del Estado». La «sospecha» sobre el Estado, se vinculaba con su falta de eficacia y eficiencia e invitaba a pensar otros actores. En este sentido, tal como indica Bresser Pereyra (1997 y 2002), el eje está puesto en la sociedad civil, y más especialmente, en la aparición de una esfera pública no estatal. La ya «crisis» del Estado, se manifestaba en términos de reajuste y reformas de carácter aperturista y neoliberal, la reducción del aparato y de apertura democrática: herramientas de gestión orientadas a la democracia directa y participativa. En este sentido, hacia finales de la década de 1980, se ponía en duda el alcance material de lo declarado en términos discursivos y la posibilidad de concretar esos cambios en el contexto de Estados, democráticos, cada vez más ausentes.

Esta situación de Estados «ausentes» y administraciones públicas «incapaces» no casualmente coincidió con el auge de los enfoques de la Nueva Gestión Pública y la gobernanza (Cunill Grau, 2000; Mayntz, 2006; Peters, 2005 y O’Donnell, 2010) para modificar esa organización rígida, jerárquica y burocrática (en sentido weberiano) que afectaba negativamente los resultados de las reformas. En cambio, el contexto actual es diferente al anterior, pues los Estados están otra vez en el tapete. El protagonismo del Estado ha crecido en relación con el mejoramiento de sus capacidades administrativas y políticas (Iazzetta, 2005). Sin embargo, y como señalan Messner (1999) y Thwaites Rey (2008: 1) la denominada fase global del capitalismo en las últimas décadas constituye un cambio trascendente en términos de las «formas de ejercicio de la soberanía estatal en cuestiones tan básicas como la reproducción material». El planteo de Messner (1999: 71) al respecto es claro: «el Estado nación es el eje y punto cardinal de nuestro sistema de coordinación político» pero, la estructura de poder monocéntrica se ha modificado y se asiste a un reparto de tipo policéntrico, lo que equivale a decir que los Estados no están solos, y comparten escenario con muchos otros actores. Esta situación, plantea una serie de desafíos para el devenir del Estado-nación tal como este se estructura, por lo menos, desde finales del siglo XIX. Parafraseando al autor y si el Estado sigue siendo el «solucionador de problemas», la posibilidad de generar una estructura global de gobernabilidad depende, en forma directa, de la exis- 
tencia de «núcleos regionales eficientes» (Messner, 1999: 76). En este contexto de transformación de la política (y, se agrega, de lo político), el Estado aparece como un «manager de interdependencia» (Messner, 1999:78). El retorno del Estado no tiene que ver, necesariamente, con la reinvención de la matriz estadocéntrica en términos del desarrollo de la industria sustitutiva, la vigencia de las economías cerradas, la regulación estatal de los mercados y un patrón de inflación moderada (Cavarozzi, 1991:94), aun cuando algunos de estos atributos puedan resultar familiares en el último tiempo. El retorno del Estado más bien se vincula con la cuestión de las capacidades de este complejo institucional de cara al rol que asume en el momento actual del capitalismo. En términos de Iazzetta (2005) y para el caso argentino, la recuperación de dichas capacidades se vinculó con un «piso de estatidad» sostenido en la recuperación de ciertas variables de la economía a través de las reservas monetarias y las reformas fiscales, al menos hasta $2008 .^{6}$

Al mencionar la relevancia del Estado, y su regreso a escena, deben mencionarse también los procesos de democratización existentes en América Latina desde la década de 1980. La democratización del Estado ${ }^{7}$, o en otras palabras, la reforma democrática del Estado, resulta no sólo de la existencia de múltiples actores en la arena política, sino también de los modos los que los actores se relacionan con el Estado. Autores como Cunill Grau (1997), plantean una «publificación de la administración pública», que podría analogarse a un proceso de democratización de la misma en la medida que supone, al menos, dos aspectos: un vínculo más estrecho entre el Estado y la sociedad civil y una mayor eficiencia en la «prestación de servicios al ciudadano pero, las administraciones públicas de carácter burocrático poseen un carácter rígido sostenido en una superioridad técnica y una racionalidad instrumental (Weber, 1994), siendo no necesariamente receptiva a una reforma «posburocrática» en esos términos.

Dicho esto, y al considerar las redes de políticas como una construcción analítica (Subirats, 1989) resulta muy relevante la pregunta de Jordana (1995), «cuándo se intro-

${ }^{6}$ Suele haber acuerdo en que la denominada «etapa rosa» del contexto de la posconvertibilidad (es decir, el período posterior al cese de la paridad cambiaria peso argentino/ dólar norteamericano establecida por ley desde 1991, que se inicia en 2002 pero continúa), en cuanto a considerarlo de mejoramiento general de la mayoría de las variables socio-económicas. Sin embargo, a partir de 2008, se observa un desaceleramiento de la economía y el desmejoramiento de algunas de las variables socio-económicas. La discusión sobre el devenir de la posconvertibilidad es una discusión abierta y excede ampliamente los objetivos de este escrito. Al respecto, puede consultarse el texto del Centro de Estudios para el Desarrollo Argentino (CENDA) (2010): La anatomía del nuevo patrón de crecimiento y la encrucijada de la economía argentina en el periodo 2002-2010, Cara o Ceca, Buenos Aires.

7 Los estudios sobre democratización se encuentran hoy muy incorporados a la agenda académica. Si bien estos no forman parte de los temas de este escrito, se comprende la necesidad, en especial en el caso de las democracias «jóvenes», tal es el argentino, de, no sólo democratizar el régimen político sino, esencialmente, democratizar al Estado como cuestión de igual relevancia. Iazzetta aboga lúcidamente esta afirmación: «El Estado necesario tras la democratización del régimen político no se obtiene espontáneamente y ello exige, antes que nada, aceptar al Estado como parte del proceso de democratización iniciado». Véase, Iazzetta, Osvaldo (2012), «La democracia delegativa y su cara estatal. Un abordaje del caso argentino» en O’Donnnell, Guillermo; Iazzetta, Osvaldo y Quiroga, Hugo (coordinadores), Democracia Delegativa, Prometeo, Buenos Aires (pág. 87). 
duce el Estado como categoría teórica» ¿es clarificador o es incongruente conceptualmente?» El autor retoma la noción de red para la resolución de problemas resultantes de los análisis tradicionales basados exclusivamente en las acciones de las burocracias. Su respuesta es contundente y coincide con el planteo de Oszlak (1984), en cuanto no se estaría considerando el otro carácter monolítico del Estado, éste, no es un actor unificado, sino una pluralidad de actores e incluso de burocracias. En este sentido, interesa para este trabajo recuperar al Estado -en términos de sus espacios vinculados con la gestión del desarrollo rural- con el supuesto de que continúa siendo un actor central en los procesos de elaboración de políticas públicas y, en especial, en la existencia de redes.

\subsection{Las politicas y las redes}

Las políticas públicas implican una toma de decisión sobre una cuestión (issue) determinada. Éstas, se constituyen como entidades dinámicas; no son estructuras inamovibles sino que, más bien, pueden comprenderse bajo la lógica de los procesos. Algunos autores señalan que el modo más sistemático de comprenderlas es a través de los «flujos» (Lahera Parada, 2002). Esos flujos se advierten a partir de lo que se denomina «ciclo» de las políticas públicas. Esta noción de ciclo no significa, sin embargo, identificar la política pública con un conjunto ordenado -y estancado- de pasos a seguir. Una política pública supone, en términos analíticos, un proceso de toma de decisiones e interacción subjetiva (Subirats, 1989), por lo que implica necesaria y paralelamente un proceso en el que coexisten racionalidades diversas y contradicciones. Un elemento importante para su comprensión es considerar la «red o entramado de actores» que aparecen alrededor de un problema de políticas (Subirats, 1989:44). El origen del ciclo -en el que podemos establecer el momento en el que una cuestión es socialmente problematizada (Cobb y Elder, 1993; Oszlak y O’Donnell, 1976)- el diseño, gestión y evaluación (Lahera Parada, 2002). ${ }^{8}$

Durante la década de 1990, el análisis de las redes de políticas (o policy networks ${ }^{9}$ ) constituyó uno de los aportes de la Ciencia Política al estudio de los procesos políticoadministrativos (Morata, 1991; Porras Martínez, 2001; Fleury, 2002 y Souza, 2006). En aquel contexto, en América Latina en particular, se cuestionaba el rol del Estado y se establecían las reformas de «primera» y «segunda» generación antes mencionadas. La gestión pública dejaba de pensarse estrictamente estatal y se orientaba a modos más flexibles y menos burocráticos, dando paso al enfoque de la Nueva Gestión Pública

${ }^{8}$ En este sentido, se retoma la cuestión de los «ciclos» sin desconocer la complejidad del proceso y con un sentido heurístico, y para dar cuenta de algunos momentos (o fases) de dicho ciclo. La posibilidad de observar esas fases no implica eludir la alteración de los momentos de esas fases, sus relaciones y modos de vincularse.

${ }^{9}$ Es importante destacar, que algunos términos: policy networks, policy commmunity, iron triangle son de un uso -relativamente- reciente en la literatura en español sobre políticas públicas (Véase la N.T. a Klijn, 1998). Además, debe destacarse el extendido uso de las policy networks especialmente, en los sistemas de gobernanza de la Unión Europea en el último tiempo. Véase, Börzel (1997). 
(New Public Management). La existencia de «redes» a partir de esta perspectiva de carácter relacional tenía como principal mérito la «integración del pluralismo institucional y territorial en el estudio de los procesos de decisión y elaboración de políticas públicas» (Morata, 1991:154) o la modificación de los regímenes top-down de concepción delegativa y jerárquica (Blanco y Gomá, 2003).

Como bien señala Aguilar Villanueva (2006), de este lado del mundo, el Estado desarrollador latinoamericano ha legitimado históricamente una administración pública de tipo burocrática. Por el contrario, las crisis del Estado y de las sociedades estatizadas dieron lugar a reflexionar de un modo diferente la relación Estado/ sociedad en términos amplios, y Estado/ administración pública/ sociedad civil, en términos más restringidos ${ }^{10}$. Es así como los procesos que involucran a la ciudadanía como actores políticos, no sólo en términos de accountability sino también de cara a la participación en diversos tipos de iniciativas gubernamentales, comienzan a ser cada vez más referidos. La constitución de redes como un modo posible de elaboración y ejecución de políticas permite la combinación de diferentes aspectos: los contextos regionales, el tipo de Estado, las organizaciones colectivas que de ellas participan, los recursos públicos que a ellas se asignan y la coordinación político-administrativa, entre otros (Jordana, 1995). Las posibilidades teóricas de analizar estas redes podrían caracterizarse de acuerdo al grado de estabilidad -o perdurabilidad- que las mismas poseen. ${ }^{11}$

Más recientemente han estado circulando distintos estudios sobre gobernanza o governance que integran diferentes perspectivas y niveles. Este «modelo» se constituye como opuesto al tradicional de carácter burocrático, aceptando que «el Estado no es un actor dominante en este proceso» (Zurbriggen, 2011). La gobernanza puede considerarse un tipo de red definida como el «proceso mediante el cual los actores de una sociedad deciden sus objetivos de convivencia -fundamentales y coyunturales-y las

${ }^{10}$ Como se indicó, esta relación ya había sido puesta en cuestión en los años de 1970 con el planteo de O'Donnell (1978: 1176 y ss) y su concepción del Estado como un aspecto de las relaciones sociales, y asimismo, con su esfuerzo de poder identificar la «administración burocrática que cumple tareas rutinizadas de organización general» y el «tejido habitual y poco visible de las múltiples decisiones diarias de sostén y organización de la sociedad», es decir, la mediación que el autor comprende como una forma posible de «institución estatal».

${ }^{11}$ Las redes más informales son las denominadas «redes de asuntos» (issue networks), definidas por Heclo (1978) como «un espacio de relación que se forma en la interacción frecuente de la multiplicidad de actores y, en general, sobre un tema en particular» (Zurbriggen, 2011:182). Por su parte, los enfoques neocorporatistas pueden considerarse la opción dicotómica a la red de asuntos. Más allá del énfasis de quitar al término el carácter peyorativo de su aplicación previa, Schmitter (1992), define el corporativismo [en original] como «un sistema de representación de intereses en que las unidades constitutivas están organizadas en un número de categorías singulares, obligatorias, no competitivas, jerárquicamente ordenadas y funcionalmente diferenciadas, reconocidas y autorizadas (si no creadas) por el Estado, y a las que se ha concedido un deliberado monopolio representativo dentro de sus respectivas categorías a cambio de observar ciertos controles sobre la selección de sus dirigentes y la articulación de sus demandas o apoyos» (1992:24). La definición es tentadora para el análisis de las formas de representación de intereses en el caso propuesto. Sin embargo, y siempre en este caso, las unidades en juego no se encuentran organizadas de ese modo, ni agotan las formas de representación de intereses (aun cuando el Estado esté directamente vinculado con su creación), por el contrario, estas se manifiestan de un modo no unificado en términos de sujetos y territorios, como podrá observarse en el apartado destinado a las experiencias. 
formas de coordinarse para realizarlos: sentido de dirección y su capacidad de dirección» (Aguilar Villanueva, 2006:90). ${ }^{12}$ Los procesos de gobernanza no sólo pueden ser tomados como herramientas de políticas sino que son, esencialmente, transversales a la sociedad. Si al decir de Bresser Pereyra (2002: 11) la sociedad civil es la porción de la sociedad por fuera del aparato estatal, o situada entre la sociedad y el Estado, esto es, «la forma en que la sociedad se estructura políticamente para influenciar la acción del Estado», en términos ideales, la gobernanza puede concebirse como un elemento de democratización de la sociedad civil que puede contribuir a democratizar, también, la acción estatal en su carácter de elaborador de políticas públicas. En sus diferentes posibilidades analíticas (Rhodes -citado en Zurgriggen -2011-; Mayntz, 2011), la gobernanza se presenta como una perspectiva para la comprensión de la complejidad de los sistemas de toma de decisión en contextos plurales, en los que un número de actores interactúan con el fin de lograr objetivos comunes. ${ }^{13}$

Otros autores (Peters, 2005), sitúan la gobernanza de un modo más heterogéneo en el que incluyen aquellos aspectos de carácter jerárquico, considerando, por ejemplo, una mirada amplia -y flexible- del concepto de burocracia (Olsen, 2005 y 2007). Desde la perspectiva del autor, la gobernanza se presenta como un enfoque alternativo en un intento para comprometer a la sociedad con la tarea de gobernar, reduciendo así los elementos estrictamente jerárquicos en el sistema político. Entre los autores alemanes, se destaca el estudio de Messner (1997 citado en Aguilar Villanueva, 2006). El mismo posee dos contribuciones de interés: desde la teoría de la acción, en cuanto al proceso de búsqueda y aprendizaje de los actores sociales, y desde la teoría de las redes (siguiendo los estudios de Mayntz) pero trascendiéndolos indicando la dependencia recíproca que estas genera, en cuanto a la diversidad de actores y recursos que se sustentan en cada caso. Messner (1999: 78) comprende que, cada vez con mayor peso, «la política va a tener lugar en estructuras flexibles horizontales y verticales cada vez más fuertes: estructuras en redes dentro de las sociedades, están adquiriendo cada vez mayor importancia; la conducción jerárquica, a través de una instancia política se convierte en excepción». En este sentido, no está de más advertir que estos autores comprenden la organización por redes en contextos de sociedades «avanzadas», en cuanto a la existencia de organizaciones formales, su diferenciación y autonomía. En términos sistémicos, la gobernanza resulta un medio para hacer posible la comunicación intersistémica o interorganizacional a nivel societal.

Mientras tanto, como señalan Mayorga y Cordova (2007), el término «gobernanza» pasó de señalarse como la acción de gobernar o el ejercicio del gobierno en una región a, con base en el Programa de Naciones Unidas para el Desarrollo (PNUD), a

12 Debe señalarse que Aguilar Villanueva, presenta cierto -podría decirse- temor, frente al uso de este término, considerando su gran potencialidad, aún con su «etiqueta de moda».

13 Autores como Rosanvallon (2007: 254), ponen en cuestión el valor heurístico del término indicando que, precisamente, en esa complejidad de los sistemas, la propia «decisión» pierde consistencia debilitando las instituciones democráticas, dado que el poder de la «voluntad general» queda en entredicho: «la referencia a la gobernanza puede ser comprendida también como una suerte de disfraz ideológico destinado a ocultar el naufragio del ideal democrático-repúblicano». 
constituir el marco de normas generales para individuos, organizaciones y empresas. Los problemas son muchos en estas latitudes, ya que a diferencia de Europa, y como claramente señalan los autores, «No existe en la producción bibliográfica latinoamericana un texto que sintetice y sistematice el uso de este concepto -ni de las formulaciones afines gobernanza y governance- y por ello las definiciones varían relativamente en función de los estudios de caso, tan variados en su enfoque como en los temas abordados». Al considerar el ejercicio de gobierno y su estabilidad, es posible entonces reintroducir la cuestión de la gobernabilidad. El estudio de Camou (2001: 7) avanza en este sentido, advirtiendo, sin embargo, que gobernabilidad «es una palabra rara». El autor relaciona la idea de gobernabilidad con la posibilidad de establecer parámetros para evaluar la acción gubernamental. De este modo, la propuesta habilita a pensar un esquema gravativo entre los polos: gobernabilidad/ ingobernabilidad. Para esto, se desglosan distintas dimensiones analíticas con el fin de establecer su carácter multidimensional: legitimidad, eficacia/ eficiencia y estabilidad. Se define la gobernabilidad como «un estado de equilibrio dinámico entre el nivel de demandas societales y la capacidad del sistema político (Estado/ gobierno) para responderlas de manera legítima y eficaz» (Camou, 2001: 36). A los fines de ese trabajo, la perspectiva de Camou (2001: 36) resulta de interés pues está situada como una relación entre el sistema político y la sociedad (entorno o ambiente). Aunque, a criterio de quien escribe, el trabajo enfatiza en la relación gobernabilidad-democracia, el planteo resulta sugerente en cuanto a los niveles de análisis sugeridos y los campos de acción que le correspon$\mathrm{den}^{14}$. En el caso de las «fórmulas institucionales», por ejemplo, Camou (2001: 52) establece los acuerdos entre el sistema de partidos, el sistema electoral y la ingeniería institucional (en el campo político), los pactos para conformar coaliciones estables (en el campo económico), y las «redes establecidas de comunicación entre el gobierno, los movimientos sociales, organizaciones civiles, etc.» en el campo social. Este último campo de acción gubernamental, y particularmente la red como posibilidad de comunicación resulta muy sugerente para el análisis del caso propuesto.

Finalmente, Prats (2001), en su conocido estudio De la burocracia a la gerencia y de la gerencia a la gobernanza, plantea un gobierno de carácter «interactivo», marcando la relevancia del gobierno relacional (o de redes) de interacción público-privado-civil en el plano global/ local. En este punto, sin embargo, como señala Aguilar Villanueva (2006: 127), «el gobierno no es un actor más, es el único que posee representatividad y autoridad democrática de su sociedad, pero el papel directivo se complejiza». Esto se vincula, en especial, con la condición de gobernanza en el plano del sistema político, en términos de la gobernabilidad comprendida desde Camou (2001) es decir, como posibilidad de estabilidad política. Luego de esta breve revisión literaria, se definirán a continuación los elementos conceptuales que permitirán avanzar en el análisis del caso propuesto.

${ }^{14}$ En el texto se presenta un campo de doble entrada vinculando dos dimensiones: niveles de análisis (modelos de orientación, formas institucionales y paquetes de políticas) y campos de acción gubernamental (político, económico y social). Véase Camou (2001: 52). 
Retomando la pregunta previamente referida de Jordana (1989), se considera que, al menos en América Latina, no es posible pensar las redes de políticas sin la participación del Estado. Se mencionó en la primera parte del texto la recuperación de las capacidades materiales y administrativas de este complejo institucional en el último tiempo, y lo que esto significó en términos de su aparato y, asimismo, del modo de elaborar políticas públicas. ${ }^{15}$

Dicho todo esto, interesa observar cómo el Estado se vincula a partir de redes (muchas veces organizadas desde espacios estatales) con otros actores sociales: en este caso, organizaciones colectivas de distinto grado de formalidad vinculadas con el desarrollo rural y la agricultura familiar y qué posibilidad existe, en todo caso, de organizarse como red en términos de aquello que Börzel (1997: 2) define como un «mecanismo para movilizar recursos políticos en situaciones en las que esos recursos están [...] dispersos entre los actores públicos y privados», o en los términos de Camou (2001), como vehículo de comunicación y, se agrega, de transmisión de demandas, entre el gobierno y las organizaciones. En definitiva, qué redes son posibles para la elaboración de políticas, y con qué actores.

En relación con lo anterior, en este escrito se utiliza la noción de «red» en dos direcciones. Por una parte, como vehículo de comunicación entre el Estado y la sociedad: las «redes» que, estables en el tiempo, garanticen la persistencia de la comunicación imbricando en un mismo espacio, actores estatales y de la sociedad civil. En este sentido, se la comprende entonces como una herramienta para los procesos de elaboración de políticas públicas. Por otro lado, la noción de «red» aproxima al analista a un modo de comprender la lógica vinculante entre los actores, estatales y societales, en este caso del desarrollo rural. De este modo, pueden existir redes de actores con roles importantes en diferentes momentos de la política pública, tales como el diagnóstico y/ o la implementación de acciones. Asimismo, y con el riesgo voluntarista que implica, debe señalarse que la posibilidad de utilizar redes -en el sentido antes propuestopodría resultar también la posibilidad de mejorar el diseño de las políticas públicas (Zurbriggen, 2011).

\section{Espacios para una política de desarrollo rural en Argentina}

Antes de introducir en forma directa las experiencias seleccionadas, se referirán algunos aspectos que caracterizan la política de desarrollo rural en el país, marcando los

${ }^{15}$ Como se señaló en el primer apartado, se refiere al Estado y no necesariamente al gobierno pues se trata de transformaciones que podrían perfilarse como estructuras permanentes inclusive frente a gobiernos de diferente signo político (aun cuando la direccionalidad y/ o orientación de las políticas se modifique). Argentina, luego de la crisis político-institucional, económica y social de 2001, cuenta hasta aquí con tres gobiernos constitucionalmente elegidos a través de elecciones regulares: Nestor Kirchner (2003-2007) y Cristina Fernández de Kirchner (2007-2011) y (2011-2015), ambos funcionarios miembros del Frente para la Victoria, partido político esencialmente peronista. Las próximas elecciones se realizarán en octubre de 2015, y el candidato elegido gobernará el país entre diciembre de 2015 y diciembre de 2019. 
actores más relevantes. Lo primero que debe decirse es que el desarrollo rural no fue un tema de intervención estatal sino hasta la recuperación democrática en el año 1983. Autores como Lattuada (2014: 17), señalan que «la Argentina, sin antecedentes previos en programas de desarrollo rural, con el retorno de la democracia en 1983 inició las primeras experiencias y avanzó en negociaciones con el BID y el FIDA en la última etapa de un modelo de intervención -el desarrollo rural integrado- que pronto sería cuestionado». Si bien con anterioridad y ya desde la década de 1950 en varios países de la región hablaban de desarrollo rural bajo diferentes lupas (Astori, 1987, Barsky, 1992, Bengoa, 2003), el momento -podríamos decir- inaugural para nuestro país es la década de 1980, cuando se gestiona, en el ámbito estatal, el primer programa de desarrollo rural con financiamiento internacional: el Programa de Crédito y Apoyo Técnico para Pequeños Productores del Noreste Argentino (PNEA). En los años de 1990, coincidente con las dos reformas del Estado mencionadas en el primer apartado y bajo el contexto del paradigma del desarrollo territorial rural, se ejecutaron numerosos programas $^{16}$ en el marco de la -por entonces- Secretaría de Agricultura, Ganadería, Pesca y alimentación (SAGPyA). Buena parte de estos programas contaron con financiamiento internacional (del Banco Mundial, BID y FIDA fundamentalmente) y contribuyeron a generar una «nueva institucionalidad rural» (Martínez Nogueira, 2001 y Lattuada, 2006), diagnosticada y elaborada por los organismos y sobre la que se estableció internamente un conjunto de instituciones y técnicos orientados a su gestión. Algunos de esos programas se presentaban como «soluciones» a situaciones de emergencia, especialmente en la franja de productores familiares (capitalizados y no capitalizados) que no pudieron adaptarse al ya por entonces consolidándose modelo del agronegocio (agribusiness)..$^{17}$

La situación de los años de 1990 se modifica considerablemente durante la década de 2000, y en especial a partir del año 2008. La oportunidad del ingreso en la agenda pública y de gobierno llegó de la mano de un acontecimiento trascendente para la vida política del país desde entonces: aquello que se denominó «conflicto campo-gobier-

16 Entre 1990 y 2000 es posible contabilizar los programas que siguen: Minifundio, Promoción para la Autoproducción de Alimentos (PROHUERTA) y Programa Federal para la Reconversión Productiva de los Pequeños y Medianos Productores (Cambio Rural), Programa de Reconversión de Áreas Tabacaleras (PRAT), Programa de Servicios Agropecuarios (PROSAP), Programa Social Agropecuario (PSA), Proyecto Forestal de Desarrollo o Componente de Apoyo a Pequeños Productores para la Conservación Ambiental (CAPPCA), Ley de Inversión para Bosques Cultivables ( $\left.N^{\circ} 25.080\right)$, Proyecto de Desarrollo de Pequeños Productores Agropecuarios (PROINDER), Proyecto de Desarrollo Rural de las Provincias del Noreste (PRODERNEA), Proyecto de Desarrollo Rural de las Provincias del Noroeste (PRODERNOA).

${ }^{17}$ Es importante destacar que «al hablar de agronegocio estamos recortando un modelo agrario que no refiere a un tipo de actor o cultivo específico, como la soja (...)» (Gras y Hernández, 2013: 25). Agronegocio como modelo de producción con lógicas territoriales distintas y caracterizadas por los siguientes atributos: transectorialidad, priorización de las necesidades del consumidor global, generalización del capital, estandarización de las tecnologías utilizadas y acaparamiento de tierras para la producción. Al respecto, puede consultarse, entre otros, Carla Gras y Valeria Hernández, El agro como negocio. Producción, sociedad y territorios en la globalización, Biblos, Buenos Aires. 
no» ${ }^{18}$. Es a partir de la particular coyuntura que inició este acontecimiento, que se generaron ciertas transformaciones en el aparato estatal orientado a la gestión del desarrollo rural. En la actualidad, el tema del desarrollo rural, desde una perspectiva territorial amplia, pero también desde los tratamientos más críticos, está en el tapete: tanto en la agenda académica ${ }^{19}$ como, y en especial, en la agenda política. Se presenta como una cuestión de carácter muy movedizo y los principales ejes de discusión son la interpretación de los sujetos que la comprenden (en especial el amplio espectro de productores que se denominan «familiares») y los tipos de acciones que, en este sentido, los programas y proyectos promueven. De allí que el actual es un momento central para la configuración de una política de desarrollo rural con posibilidad de trascender, en última instancia, la lógica desagregada que en ocasiones los programas promueven y que ha sido un rasgo característico hasta aquí.

Sin embargo, las modificaciones en el aparato estatal, aun marcando cambios en lo que antes se denominó «institucionalidad rural» no definen por sí mismas modificaciones en la racionalidad política enlazada, pero si presentan un contexto que permite visualizar mejor las diferencias, contradicciones y falta de consenso que se reproducen al interior del Estado y que dan cuenta, en todo caso, de racionalidades políticas diferentes.

Es en particular con la creación de la Subsecretaría de Agricultura Familiar que se abre un espacio para la gestión de los programas más vinculados con productores bajo la línea de pobreza, con serias dificultades de comercialización y sin acceso créditos ${ }^{20}$.

18 Desde el año 2002, Argentina vuelve a aplicar un sistema de retenciones (según el tipo de producto), a las exportaciones. Durante marzo de 2008, se anunció un cambio en la estructura del impuesto: se aplicaría, a partir de la resolución 125 (desde entonces «la 125»), un sistema de retenciones móviles. Esto provocó una crítica generalizada de buena parte de las organizaciones más tradicionales de representación sectorial y de un conjunto de productores, ya que suponía, en ese momento, un aumento de la presión fiscal sobre el sector.

19 Aunque excede los límites del objetivo propuesto en este trabajo, es pertinente mencionar muy brevemente la amplísima discusión sobre desarrollo rural, en las últimas tres décadas particularmente. En los últimos años, especialmente a comienzos de la década del 2000, se destaca el énfasis, académico y político, en la perspectiva del «desarrollo territorial rural» (DTR) (Schejtman y Berdegué, 2003; Schejtman y Barsky, 2008; Manzanal, Neiman y Lattuada, 2006; Lattuada, Márquez y Neme, 2012 entre otros), una perspectiva de carácter territorial con influencia del institucionalismo que da lugar a «casi» un nuevo paradigma (Manzanal, 2006). Estudios más recientes sostienen, en cambio, una perspectiva diferente indicando que el «desarrollo» (asociado a una política determinada o como resultado de una) es un «diseño» que se utiliza para «ocultar el funcionamiento naturalmente desequilibrado del sistema político» enunciando así «idealistas propuestas de gestión pública» que resultan un instrumento útil parael poder hegemónico (Manzanal, 2013: 19). Desde esta mirada crítica, muy asociada a los estudios de Arturo Escobar, se indica cómo los organismos internacionales construyen un particular control social frente a la posibilidad de establecer «reglas del juego» planteando, además, la necesidad de una nueva organización del sistema político.

20 Este espacio ha tenido vinculación y control de diversos programas de desarrollo rural desde 2008, en este momento bajo la figura de Subsecretaría de Agricultura Familiar. En ese ámbito se ejecutan las acciones enmarcadas en PROINDER (financiado por el BIRF) y PSA, cuyas acciones a cargo forman parte de uno de los componentes de PROINDER, el de Apoyo a las Iniciativas Rurales (AIR) (Román y Soverna, 2005). Finalmente, en diciembre de 2008 se crea el Plan de Apoyo a Pequeños y Medianos Productores (PAPyM). 
Debe decirse, además, que esta agencia -que a partir de 2014 tomará el rango de Secretaría- maneja fondos casi exclusivamente nacionales, es decir, no confluyen en su órbita, los programas de desarrollo rural con financiamiento internacional vigentes en el país $^{21}$. En octubre de 2009 se modifica la Ley de Ministerios. A partir de esta modificación, se crea el Ministerio de Agricultura, Ganadería y Pesca (MAGyP), reemplazando, con una mayor jerarquía institucional ${ }^{22}$, a la Secretaría de Agricultura, Ganadería, Pesca y Alimentación (SAGPyA) ${ }^{23}$. En diciembre de ese año se crea la Unidad para el Cambio Rural (UCAR) ${ }^{24}$. En los considerandos de la resolución se destacan los proyectos y programas de desarrollo rural existentes al momento y cuya ejecución estaba en manos de la ex SAGPyA.

En los años de 1990, la SAGPyA se concentraba en la ejecución de los proyectos, la mayoría de ellos con financiamiento internacional; en rigor, la SAGPyA no constituía un actor «elaborador» de políticas públicas, su rol «estaba acotado a lo puramente administrativo y de control burocrático, sin capacidad para la elaboración de políticas»; de este modo, la presencia del MAGyP se presentó como «una oportunidad (...) debido a la mayor jerarquía otorgada a la problemática del sector agropecuario y del medio rural en la estructura del Estado, así como la priorización del desarrollo rural y la construcción institucional en su estructura funcional» (Lattuada, Márquez y Neme, 2012: 34). Los proyectos existentes (previo a los cambios ocurridos en el marco del MAGyP) poseían, en forma individual o grupal, estructuras organizacionales de ejecución ad hoc. Tomando esto en consideración, el propósito de generar -en la nueva estructura del Ministerio- una «Unidad» para el Cambio Rural fue el de «centralizar las funciones relacionadas a planeamiento, negociación, formulación, administración, finanzas, control de gestión, monitoreo y evaluación» en su ámbito, tal como lo indica la resolución citada. En la noción general de «coordinar y centralizar» distintas funciones, no sólo es importante observar los elementos internos que constituyen la UCAR sino también el marco de relaciones que se plantea a partir de estas funciones.

${ }^{21}$ En sus inicios, la subsecretaría tuvo una participación importante en el Foro Nacional de la Agricultura Familiar (FoNAF). Este instrumento de «diálogo político» (como suele denominarse) se crea a partir de la participación de Argentina en la Reunión Especializada de Agricultura Familiar del Mercosur (ReAF) durante el año 2004, estableciéndose en el año 2006 a través de la resolución 132/ 2006.

22 Se menciona la idea de jerarquización institucional, al menos provisoria y comparadamente, en cuanto al pasaje formal de secretaría a ministerio. Sin embargo, la pregunta de Craviotti (2013) respecto de si estos cambios representan, en rigor, un fortalecimiento institucional o una debilidad estructural resulta muy ilustrativa de la actual coyuntura y forma parte de un debate actual respecto de la temática presentada.

${ }^{23}$ No es el primera vez en la que agricultura posee un ministerio: la primera cartera de Agricultura, Ganadería y Pesca se creó en 1898, en un momento fundacional del Estado nacional durante la segunda presidencia de Julio A. Roca. Para lo que sigue de este apartado, tomamos como referencia lo señalado en Nogueira (2015).

${ }^{24}$ Es importante mencionar que el origen «histórico» de la UCAR, ocurre a partir de la Unidad Coordinadora Nacional de los programas PRODERNEA y PRODERNOA. Ya en 2003, esta unidad tenía como coordinador al responsable de PROSAP que, tiempo después, coordinó también la UCAR (Véase Lattuada, Márquez y Neme, 2012). 
En este sentido, esta instancia tiene el «rol» de articular las relaciones con otras instancias, del mismo MAGyP pero también externas: con el Ministerio de Economía y Finanzas Públicas, con el Ministerio de Relaciones Exteriores, Comercio Internacional y Culto, con los organismos de financiamiento y cooperación internacional y con otros organismos de la administración pública, nacional y provincial.

Estas características generales sobre actores e instrumentos habilitan a pensar ciertos mecanismos que adquieren los atributos y funciones de las redes en el tema convocante. Luego de esta descripción que, por cierto, adelanta algunos rasgos que serán considerados, a continuación se avanza sobre las redes existentes -o no- en la materia.

\section{4. ¿Y las redes?}

En el punto previo se señalaron las instancias de mayor relevancia en el entramado de espacios estatales vinculados al desarrollo rural y la agricultura familiar. Puede notarse que en la descripción de los mismos, aparecen términos como «diálogo político», «relaciones inter-agencia», «relaciones con organizaciones de la sociedad civil», «coordinación», «optimización de recursos», etc. El planteo de una política de desarrollo rural en estos términos permite suponer - a priori- las articulaciones en los distintos niveles (a nivel del aparato estatal), pero también hacia afuera, con diversas instancias colectivas con distinto grado de institucionalidad que participan de esa coordinación. Para avanzar sobre este supuesto, se tomarán aquí cuatro experiencias de «redes» en materia de desarrollo rural. Dichas experiencias tienen un punto central en común: han sido promovidas y organizadas desde el Estado (a través de distintos instrumentos y con mayor o menor intensidad), y sólo en algunos casos con participación de actores de la sociedad civil. Lo anterior refuerza el rol del Estado -y el gobiernocomo «nodo» de la red confluyendo en este complejo institucional una serie de rasgos ya mencionados en el primer punto del trabajo: 1) su incidencia en el marco de normas (reglas y condiciones) de funcionamiento, 2) que posee representatividad legal y legítima, aun cuando no es un actor unificado (en términos de las racionalidades políticas en juego), 3) se complejiza el proceso de gobierno: las redes de actores (como posibilidad de la acción colectiva), «requiere[n] de una agencia de gobierno con la función de resolver o facilitar ese dilema [refiere al dilema de la acción colectiva]» (Aguilar Villanueva, 2006: 126). Dicho esto, se considerarán a continuación cuatro experiencias muy vinculadas entre sí: 1) Comisión de Desarrollo Rural (CDR), 2) Foro de Políticas Públicas Rurales (FPPR); 3) Foro Nacional de la Agricultura Familiar (FoNAF) y 4) Consejo de la Agricultura Familiar, Indígena y Campesina (CAFIC).

La Comisión de Desarrollo Rural se creó en el año 1999 por una resolución interna de la por entonces SAGPyA. Sus funciones eran, entre otras, «proponer medidas destinadas a lograr complementariedad y eficiencia entre programas, proyectos y jurisdicciones», «sugerir medidas para facilitar la coordinación con las provincias y con otros organismos», «formular recomendaciones a otras áreas de gobierno» en relación con el desarrollo rural. De la información relevada se desprende que la CDR surge 
como una propuesta del Componente de Fortalecimiento Institucional del Proyecto de Desarrollo de Pequeños Productores Agropecuarios (PROINDER), presidida por el Subsecretario de Agricultura. En el momento de creación de este espacio, ya habían transcurrido dos reformas del Estado, y buena parte de los programas de desarrollo rural estaban en ejecución. De hecho, existía una multiplicidad de programas sin aparente coordinación común, cada uno tenía una coordinación y una estructura propias. La CDR, según lo relevado, intenta ser un «mecanismo de coordinación» de esa gran cantidad de programas. No era un espacio en donde participaran organizaciones de la sociedad civil, u otros organismos estatales (aunque hubo excepciones), era un espacio de articulación inter-programa, con los «responsables» de cada programa. Los actores consultados manifiestan que fue un espacio muy valioso, aunque no necesariamente en cuanto a la coordinación y articulación de los programas (que actuando en el territorio muchas veces se solapan en sus objetivos y acciones, duplicando recursos materiales y humanos). En particular, dos funciones se caracterizan como muy positivas: 1) la promoción del diálogo entre los programas y 2) la generación de un importante caudal de información sobre la implementación de los programas. Esto permitió lograr cierta horizontalidad inter-programa. La CDR mantuvo su existencia durante la totalidad de los años de gestión de los programas, con mayor o menor intensidad en sus sesiones, acciones y presencia de los coordinadores de programas en cada caso. En rigor, efectivamente se logró una articulación entre los programas, pero no trascendió del ámbito interno, es decir, no participaron allí los actores colectivos vinculados con el desarrollo rural. La Comisión fue un espacio plenamente público-estatal, y su mayor función tuvo que ver con la generación de información que se utilizó (y se utiliza) como fuente de diagnóstico para muchas de las intervenciones en esta materia existentes en la actualidad. ${ }^{25}$ De hecho, mucho de lo producido por la comisión, e incluso su esquema de funcionamiento, se toma en consideración para la generación de la segunda experiencia que nos interesa destacar: el Foro de Políticas Públicas Rurales. Este foro se formaliza también por resolución interna de la SAGPyA. Su objetivo era «discutir, evaluar y proponer las políticas institucionales más apropiadas a los objetivos de desarrollo y promoción de las áreas rurales» (Documento del FPPR, 2006). A diferencia de la CDR, el Foro contó con la participación de actores estatales y no estatales: la presidencia del Instituto Nacional de tecnología Agropecuaria (INTA), funcionarios de la SAGPyA, un legislador, académicos y dirigentes gremiales (idem). El Foro produjo una propuesta de creación de un Área de Desarrollo Rural (ADR) en el marco de la SAGPyA (aún no se había creado el actual ministerio), promoviendo distintos espacios, entre los que se destacan los de dialogo político, de políticas públicas y desarrollo rural y de operaciones. La propuesta del Foro, y en especial de la ADR no se concretó (aunque si se observa en detalle, buena parte de su intencionalidad política apa-

${ }^{25}$ Si bien cada una de las reuniones de la CDR fue documentada, no se ha podido acceder a la información de las mismas, razón por la que la reconstrucción de la experiencia fue posible en base a relatos orales y menciones en otro tipo de documentos. 
rece a través de la UCAR). En todo caso la existencia de este espacio «amplio» el número y tipo de actores, y las organizaciones gremiales, en especial la Federación Agraria Argentina (FAA). ${ }^{26}$

El documento del Foro señala con relevancia la que aquí se mencionará como la experiencia más acabada en materia de redes que ha tenido influencia en la gestión pública del desarrollo rural en el último tiempo: el Foro Nacional de la Agricultura Familiar (FoNAF), siendo esta la tercera experiencia que se mencionará. Como se adelantó, este espacio fue, en buena medida, resultado de la participación del gobierno de Argentina, por entonces a través de la SAGPyA, de la ReAF, en el año 2004. Aunque la resolución que le otorga identidad institucional data de 2006 (es incluso previa a la del FPPR) se inaugura en setiembre del año 2005 con el objetivo de lograr un «diagnóstico participativo e integral» de la cuestión de la agricultura familiar. El Foro, si bien fue un espacio promovido por el Estado, es una de las primeras experiencias que nuclea a un número importante de organizaciones del sector agropecuario, no sólo de los sectores medios y pampeanos (como podría considerarse la FAA) sino también otras organizaciones de la agricultura familiar, campesina e indígena «extra» pampeanas, vinculadas con las economías regionales. En su marco, se habría logrado una «gestión compartida de lo público». Como productos de esta co-gestión, se destacan dos documentos: el Documento de Mendoza y el de Parque Norte, en los que se hace manifiesto un diagnóstico efectuado de modo «participativo e integral» (Documento del FPPR, 2006). Una de las cuestiones de mayor relevancia es el acuerdo respecto de cómo definir la agricultura familiar, es decir, cómo definir a las poblaciones beneficiarias de los programas de desarrollo rural. ${ }^{27}$

El momento en el que tiene su origen el FoNAF es un momento de cierto esplendor de los Estados de la región (vinculado esto con la recuperación de ciertas capaci-

${ }^{26}$ La Federación Agraria Argentina (FAA) es una organización gremial cuyo origen data del año 1912 en la localidad de Alcorta (se llamó al acontecimiento que le dio origen "Grito de Alcorta", localidad ubicada en la provincia de Santa Fe, en la región pampeana del país, siendo esta la zona más rica en términos agrícola-ganaderos. Fue creada como respuesta a una serie de conflictos por los costos de insumos, libertad de siembra, contratos leoninos, etc. Lattuada (2006: 67) señala que «la FAA sería la expresión de los pequeños y medianos productores familiares (...) cuyos intereses se contraponían a los de los grandes terratenientes...».

${ }^{27} \mathrm{Si}$ bien se trata de una categoría abierta y en permanente discusión, se señala que el Censo Nacional Agropecuario de 2002 (último disponible), identifica que alrededor del 66\% del total de las explotaciones agropecuarias son de carácter familiar. Esto nuclea a 218.868 unidades que ocupan el 13\% del total de la superficie agropecuaria del país. Para definir este número se considera que: 1) el productor o socio trabaja directamente en la explotación, 2) se utiliza mano de obra familiar (y en general, no se contrata trabajo asalariado, 3) no son sociedades anónimas o similares. También se considera que la agricultura familiar es un «modo de vida» orientado por una racionalidad no capitalista, cuya consideración varía notablemente en términos territoriales de acuerdo a las regiones agroecológicas de Argentina. El tema tiene gran amplitud y existen una gran cantidad de trabajos que lo estudian. A modo informativo, se señala el texto de Marcela Roman, «Agricultura familiar: concepto, polémicas y algunas cifras para la Argentina», en Revista Ciencia Hoy, volumen 24, número 140, agosto de 2014. 
dades mencionadas en el punto 1) En el caso de Argentina, la recuperación de esas capacidades otorgó una estabilidad a los procesos que permitió mirar, al menos a mediano plazo, qué hacer con las políticas públicas. Regionalmente, y en paralelo con esa recuperación, que también se notó en otros países, en especial en Brasil, el MERCOSUR también mostró un despertar que, en materia de desarrollo rural, se traduce en el contexto de la ReAF en el que se congregan los intereses, aún dispersos, de generar un espacio como el del Foro. La experiencia tuvo entonces un período de existencia exitosa hasta, podría decirse, el año 2008. Con el devenir del ya referido conflicto con el «campo», comenzaron a observarse las grietas en términos de las representaciones de los sujetos en cada caso. De allí surge la Federación de Organizaciones Nucleadas de la Agricultura Familiar (FONAF), un espacio gremial instituido que se presenta en palabras de su presidente como una «nueva representación de los intereses sectoriales» y como un «interlocutor válido» de cara a los diferentes espacios estatales. Esta mutación modifica el carácter del diálogo político, entre las organizaciones, y desde las organizaciones con los diferentes espacios estatales. En primer lugar, el retiro del Foro, y más en particular, las diferencias radicales con el gobierno, marcaron el camino de salida para la organización sectorial de mayor importancia comprometida desde 2005, la FAA. A partir de aquél año se generó un contexto especularmente diferencial al de 2004 en términos de oportunidad política para la consolidación de una política de desarrollo rural, y lógicamente, también para estas pocas estructuras en red que habían funcionado con un éxito, por cierto, limitado. Desde 2008 y hasta la actualidad, las rispideces entre las organizaciones tradicionales del sector rural y el gobierno (el segundo de Cristina Fernández de Kirchner) no se han modificado radicalmente. Si bien el conflicto no alcanza los matices de alta visibilidad mediática y agresividad pública por parte de diferentes actores, permanece latente la tensión de uno y otro lado. Con la disolución del FoNAF en su sentido original y la posterior creación de la Federación (FONAF), los sectores de la agricultura familiar allí nucleados (fundamentalmente organizaciones formalizadas, cooperativas y movimientos sociales vinculados con la agricultura campesina e indígena no pampeana) parecen tener una muy cercana relación con la actual Secretaría de Agricultura Familiar. Asimismo, en la prensa escrita fueron apareciendo entre junio y agosto de 2014 una serie de notas que mostraban un acercamiento bastante novedoso entre los funcionarios a cargo de esa cartera y la UCAR (véase diario La Nación). La materialización de ese acercamiento se materializa en la creación de la cuarta experiencia que interesa dejar planteada: el Consejo de Agricultura Familiar, Indígena y Campesina (CAFCI). Ciertamente, es muy prematuro realizar un análisis que no destaque exclusivamente sus elementos coyunturales, pero sí es posible observar críticamente la existencia de este «nuevo» espacio como una especie de «punto de llegada» de los caminos que han andado las redes en esta materia. El Consejo se crea por una resolución interna del Ministerio de Agricultura, Ganadería y Pesca del mes de agosto de 2014. Se señala en su artículo primero, la competencia del mismo «como un espacio participativo para debatir y generar consensos sobre diseños e implementación de políticas públicas estratégicas para el desarrollo sustentable y consolidación de la Agricultura Familiar, Campesina e Indígena». 
Asimismo, lo integrarán los siguientes actores: las máximas autoridades de la Secretaría de Agricultura Familiar, del INTA, el SENASA, y la UCAR y «un representante de cada organización Campesina, Indígena y de la Agricultura Familiar de alcance nacional (...)» (artículo 2). De todos los espacios mencionados, es este Consejo el que incorpora una mayor cantidad de actores. Resulta particularmente relevante la inclusión, por primera vez, de las dos carteras dentro del ministerio vinculadas al desarrollo rural: la SAF y la UCAR ${ }^{28}$. Entre agosto y diciembre el Consejo se reunió en dos oportunidades mientras se discutían ya desde hacía un tiempo, proyectos para la sanción de una Ley de Agricultura Familiar. Entre ellos, el Proyecto de «Ley de Reparación Histórica de la agricultura familiar para la construcción de una nueva ruralidad en Argentina» promovida por la FONAF, muy vinculado con el ethos que a la SAF le interesaba imprimirle. La ley se sanciona el día 1 de diciembre de 2014. Si bien este nuevo instrumento legislativo no está aún reglamentado y es imposible, por tanto, esbozar algún análisis de sus alcances, resulta importante realizar uno breve, de carácter prematuro, siempre en la línea del propósito de este escrito. La Ley 27.118 de Reparación Histórica de la Agricultura Familiar para la construcción de una Nueva Ruralidad en Argentina posee algunos objetivos específicos relevantes y novedosos, más allá de sus objetivos más amplios y generales, que se transcriben a continuación: artículo 4, puntos e, i y j: «fortalecer la organización y movilidad social ascendente de la agricultura familiar, campesina e indígena, con especial atención a las condiciones y necesidades de la mujer y la juventud rural»; «garantizar los derechos de acceso y a la gestión de la tierra, el agua, y los recursos naturales en general, las semillas, el ganado y la biodiversidad estén en manos de quienes producen alimentos» e «implementar acciones específicas para los pueblos originarios y sus comunidades». Estos aspectos se encuentran, en nuestra opinión, muy orientados a la SAF, dentro del ámbito estatal, y la FONAF, como espacio colectivo de un conjunto de organizaciones de la agricultura familiar. La ley avanza también sobre la conversión del Registro Nacional de la Agricultura Familiar (RENAF) ${ }^{29}$ de voluntario a obligatorio, teniendo los productores la obligación de inscribirse en forma individual o asociativa, también enmarcado hasta

${ }^{28}$ Debe decirse que uno de los principales «desencuentros» entre éstas, resulta de una concepción diferencial, aunque no necesariamente contradictoria, de los sujetos de intervención de los programas de desarrollo rural. Mientras que en el primer caso se observa una mirada de carácter universal, de construcción de ciudadanía en los clásicos términos de Marshall (2004) de sujetos históricamente desplazados en la sociedad argentina: el pequeño productor campesino, y en especial, el aborigen; en el segundo, las acciones se orientan a otras problemáticas: la organización económica, la producción y tecnología, y el acceso a los mercados. Asimismo, las características organizacionales de las agencias y los estilos de liderazgo en cada caso son muy distintos también. Mientras la SAF presenta un carácter menos burócratico y más comprometido con las distintas organizaciones campesinas e indígenas en términos de protagonismo político; la UCAR reviste un rol, en apariencia al menos, más clásicamente familiarizado con estructuras más jerárquicas y burocráticas.

29 El Registro Nacional de la Agricultura Familiar (RENAF) y la Unidad de Registro Nacional de la Agricultura Familiar se crean por la resolución 255 del año 2007. Este instrumento, originalmente de carácter voluntario, tiene como objetivo la posibilidad de generar información sobre los potenciales destinatarios de las acciones estatales. 
aquí en la SAF. Interesa, sin embargo, a los fines de este trabajo, señalar qué organismo será la autoridad de aplicación de la reciente norma. El artículo 9 de la misma indica que éste será el Ministerio de Agricultura, Ganadería y Pesca, y que «la autoridad de aplicación dará participación al Consejo de Agricultura Familiar, Campesina e Indígena creado por la resolución 571 del MAGyP». Esto es, el muy recientemente creado CAFCI, espacio que se presenta, en principio, como posibilitador de cierta concertación en materia de desarrollo rural cobra una relevancia central en los alcances y aplicación de la ley. El dato no resulta menor y es alentador de cara al futuro de las intervenciones con el objetivo de establecer una orientación que trascienda los tiempos coyunturales de los programas.

En este apartado, se han descripto experiencias de vinculación entre los espacios estatales y los actores de la sociedad civil que planten un funcionamiento en red. Tres de ellas, ya no existen, o han mutado en su estructuración original. En todas, el Estado, a través de distintos espacios (SAGPyA, UCAR, SAF), ha estado presente con menor o mayor nivel de protagonismo. La última experiencia, en todo caso, es la que habilita un interrogante en cuanto a su devenir, en la medida que, al menos, se presenta como un vehículo de comunicación «genuino» de cara a la participación de los espacios estatales, y de organizaciones de la sociedad civil.

\section{A modo de conclusión}

Si la política hoy se compone de «estructuras en redes dentro de las sociedades» (Messner, 1999:78), y cada vez más surgen «contornos de una sociedad en red en la que el Estado Nacional cumple siempre funciones de articulación hacia adentro y hacia afuera, en el que las instituciones no estatales y las empresas privadas deben asumir la responsabilidad por el desarrollo cuando hay que aminorar y resolver conflictos y crisis» (Messner, 1999: 77), la pregunta sobre el rol del Estado en la elaboración de políticas públicas, y más aún, en redes de políticas, cobra relevancia. En una aparente contradicción, se expanden las redes en los distintos sistemas políticos, pero el Estado continúa, en percepción de quien escribe, teniendo ese rol de coordinación y regulación que no puede tener otro actor. Si bien el planteo de Messner (1999) resulta en términos de la construcción de una gobernabilidad «global» en el plano normativo, es posible reflexionar con ese argumento a nivel micro y de cara a las transformaciones internas de los Estados y la administración pública, por un lado, y las políticas públicas, por otro. No obstante, la respuesta a la pregunta de Jordana que se mencionó al principio cobra vigencia y es afirmativa. El Estado sigue teniendo un rol, como organizador, pero también como des-organizador de ciertas estructuras en red. En las experiencias que se han relatado, es el Estado quien moviliza recursos (materiales, humanos y simbólicos), aun cuando en uno de los casos -el FoNAF- se observa cierta autonomía de muy corta duración hasta mutar en un espacio gremial -la FONAF-, con una estrecha relación con la SAF. En este sentido, aun cuando existen cada vez más cantidad de actores de la sociedad civil en la arena política, el rol preponderante en el armado y en la estrategia de la red, sigue a manos de espacios estatales. En este sentido, no deja de 
ser sugerente la reflexión de O’Donnell a comienzos de la década de 1970, y en contextos del autoritarismo burocrático, cuando explicaba que, a pesar de los procesos de pluralización de las sociedades, no necesariamente la mayor cantidad de actores se traduce en procesos de democratización de las estructuras de poder. En términos micro y contextos diferentes, si bien los espacios de políticas se conforman como estructuras más flexibles y participativas en términos teóricos, tales adjetivos no necesariamente se garantizan en las prácticas y esto contribuye a que las redes de políticas sigan estando situadas «en el papel» y no puedan trascender el ámbito de lo coyuntural para convertirse en una herramienta de utilidad en el diseño de políticas. El Estado, a través de sus distintos espacios, y parafraseando a Messner (1999), continúa en los contornos e incluso los delinea, al menos en las experiencias trabajadas en este artículo.

Al retomar la cuestión de la «red» en los sentidos propuestos, como vehículo para una comunicación con cierta estabilidad imbricando espacios estatales y de la sociedad civil para la elaboración de políticas públicas, se observan algunos esfuerzos para trascender el ámbito de la acción estrictamente burocrática, que de acuerdo a lo observado, permitiría señalar, de un modo progresivo, redes estrictamente estatales, como la CDR; redes, fomentadas desde un espacio estatal pero integradas, sólo por períodos breves, por actores de la sociedad civil, el FoNAF, y redes «mixtas» en la medida que integran actores de los espacios estatales diversos vinculados con el desarrollo rural (e incluso con el sector agropecuario en términos globales), de muy corta duración: FPPR, y de reciente comienzo y desarrollo abierto: el CAFCI. En base al análisis de estas experiencias, uno de los factores que es posible considerar para constituirse como una red estable y vinculada con el diseño y la implementación de acciones, resulta de los roles de articulación y coordinación que tendrán allí los espacios estatales, en el sentido antes referido por Messner (1999), como «manager de la interdependencia». Se considera que la presencia de los espacios estatales plantea algunos desafíos que presentan situaciones de suma cero: una red donde el Estado sea la acción, y otra donde la habilite -sin cooptarla-. En el caso de CAFCI, este riesgo podría evitarse en la medida que su gestación está relacionada en forma directa con la gestación de una Ley (en cuya sanción estuvieron involucrados la mayoría de los actores que formó parte de las experiencias mencionadas), y que es esa norma la que, en principio, habilita a esta red -mixta- a constituirse como organismo de aplicación. Sin embargo, bien se sabe que la existencia de una norma de estas características, no garantiza estabilidad en las prácticas, ni sustentabilidad en el tiempo.

En síntesis, esta última experiencia, si bien aún no presenta acciones que puedan analizarse, resulta un acontecimiento en dos sentidos: 1) es una «fórmula institucional» (Camou, 2001: 53) que nuclea a actores públicos, estatales y societales, de racionalidades diversas (aunque no menciona a las clásicas organizaciones sectoriales y sí a «organizaciones campesinas y de la agricultura familiar», sobre las que no se tiene mayor precisión en la norma), y 2) se constituye como el organismo de ejecución de la Ley 27.118 con el objetivo de formar un espacio participativo de generación de consensos para la implementación de políticas estratégicas y sustentables. Como suele decirse «Hecha la ley, hecha la trampa», a las pruebas habrá que remitirse tiempo después. 
En definitiva, la posibilidad de organizar redes como estrategia para la elaboración de políticas públicas, resulta también la posibilidad de establecer el equilibrio necesario para que los actores puedan discutir estrategias y generar consensos, o al menos acordar cuestiones. Las redes, entonces, no sólo pueden constituirse como una herramienta sino que invitan a reflexionar sobre el tejido que une a los actores, en términos analíticos y en los contextos actuales.

\section{Bibliografic}

Aguilar Villanueva, L. (2006). Gobernanza y gestión pública. Fondo de Cultura Económica, Buenos Aires.

Astori, D. (1984). Controversias sobre el agro latinoamericano. Un análisis crítico, Clacso, Buenos Aires.

Bengoa, J. (2003). «25 años de estudios rurales» en Sociologías, Porto Alegre, año 5, nº 10, pp. 36-98.

Blanco, I y Gomá, R. (2003). «La crisis del modelo de gobierno tradicional. Reflexiones en torno a la governnace participativa y de proximidad» en Gestión Pública, n 1 , pp.14051479 .

Börzel, T. (1997). «¿Que tienen de especial los policy networks? Explorando el concepto y su utilidad para el uso de la gobernación europea» en European Integration Online Papers (EIOP) vol 1: http://eiop.or.at/eiop/texte/1997-016 ${ }^{\mathrm{a}}$.htm. Consultado el 11/04/14.

Bresser Pereyra, L. C. (1997). «Prólogo» en Cunill Grau, Nuria (1997). Repensando lo público a través de la sociedad. Nuevas formas de gestión pública y representación social. $\mathrm{CLAD} /$ Nueva Sociedad, Caracas.

Bresser Pereyra, L. C. (2002). «Sociedad civil: su democratización para la reforma del Estado» en Revista Res publica, $\mathrm{n}^{\circ}$ 2, pp. 9-54.

Camou, A. (2001). Los desafios de la gobernabilidad. FLACSO/IISUNAM/ Plaza y Valdés, México.

Cavarozzi, M. (1991). «Más alla de las transiciones a la democracia en América Latina», en Nueva Época, Revista de Estudios Políticos, $\mathrm{n}^{\circ} 74$, pp.85-111.

Cobb, R y Elder, C. (1993). «Formación de la agenda. El caso de la política de ancianos», en Aguilar Villanueva, L. (Ed). Problemas públicos y agenda de gobierno. Porrúa, México.

Carviotti, C. (2013). La agricultura familiar en Argentina: ifortalecimiento institucional y debilitamiento estructural? Ponencia presentada al Congreso de la Asociación Latinoamericana de Sociología, Santiago de Chile.

Cunill Grau, N. (1997). Repensando lo público a través de la sociedad. Nuevas formas de gestión pública y representación social. CLAD/ Nueva Sociedad, Caracas.

Doz, Y. (1996). «The evolution of cooperation in Strategic Alliances: initial conditions or learning processes?, en Stratgeic Management Journal, $\mathrm{n}^{\circ}$ 17, pp. 55-83.

Evans, P. (1996). «El Estado como problema y solución», en Revista Desarrollo Económico, vol. $35, n^{\circ} 140$, pp. $21-54$.

Fleury, S. (2002). «El desafío de la gestión de redes de políticas», en Instituciones y Desarrolllo, $\mathrm{n}^{\mathrm{o}} 12-13$, pp. 1-27.

Heclo, H. (1978). «Issue Networks and the Executive Establishment» en The New Political System. American Enterprise Institute, Washington DC.

Iazzetta, O. (2005). «El gobierno de Kirchner y los desafíos democráticos pendientes», en Temas y Debates, $\mathrm{n}^{\circ}$ 10, pp.35-55. 
Jordana, J. (1995). «El análisis de los policy networks: ¿Una nueva perspectiva sobre la relación entre políticas públicas y Estado», en GAPP, nº 3, pp.77-88.

Klijn, E (1998). «Policy networks: an overview», en Kickert, W.J.M. \& Koppenjan, J.F. (editores), Managing complex networks. Sage, Londres.

Kreimer, P y Thomas, H. (2007). «Hacia una estrategia de investigación. Las alternativas teórico-metodológicas y la elección de las técnicas». Documento de Trabajo.

Lahera Parada, E. (2002). Introducción a las políticas públicas. Fondo de Cultura Económica, México.

Lattuada, M; Marquez, S y Neme, J. (2012). Desarrollo Rural y politica. Reflexiones sobre la experiencia argentina desde una perspectiva de gestión. Ciccus, Buenos Aires.

Levi, L. (1982). «Gobierno», en Bobbio, N; Mateucci, N y Pasquino, G. Diccionario de Politica, Tomo I, México Siglo XXI.

Manzanal, M. (2006). «Regiones, territorios e institucionalidad del desarrollo rural», en Manzanal, M; Neiman, G y Lattuada, M (Comp.) (2006). Desarrollo rural, organizaciones, instituciones y territorios. Ciccus, Buenos Aires.

Manzanal, M. (2013). «Poder y desarrollo. Dilemas y desafíos frente a un futuro ¿Cada vez más desigual?», en Manzanal, M y Ponce, M. La desigualdad ¿del desarrollo? Controversias y disyuntivas del desarrollo rural en el norte argentino. Ciccus, Buenos Aires.

Manzanal, M y Neiman, G. (2010). Las agriculturas familiares del Mercosur. Trayectorias, amenazas y desafios. Ciccus, Buenos Aires.

Manzanal, M; Neiman, G y Lattuada, M. (Comp) (2006). Desarrollo rural, organizaciones, instituciones y territorios. Ciccus, Buenos Aires.

Marshall, T.H. (2004). «Ciudadanía y clases social», en Marshall, T. H y Bottomore, T. Ciudadanía y clase social. Losada, Buenos Aires.

Martínez Nogueira, R. (2001). «La gestión pública agroalimentaria y rural en América Central: senderos y tareas», en Revista del CLAD, $\mathrm{n}^{\mathrm{0}} 20$, pp. 1-20.

Mayntz, R. (2006). «Governance en el Estado moderno», en Postdata, Buenos Aires, n 11, pp. 103-117.

Mayorga F y Cordova, E. (2007). «Gobernabilidad y gobernanza en América Latina», en Working Paper NCCR Norte-Sur IP8, Ginebra.

Messner, D. (1999). «La transformación política del Estado y la política en el proceso de globalización», en Revista Nueva Sociedad, n 163, pp. 71-91.

Messner, D. (1997). The network society. Londres, Frank Cass.

Moratta, F. (1991). «Políticas públicas y relaciones intergubernamentales», en Documentación Administrativa, $\mathrm{n}^{\mathrm{o}} 224-225$, pp. 153-166.

Nogueira, M. E. (2013). «Agricultura familiar y políticas públicas en la Argentina de los últimos años. Algunas reflexiones en torno a una relación compleja», en Revista Trabajo y Sociedad n ${ }^{\circ} 21$, Santiago del Estero, s/d.

Nogueira, M. E. (2015). «Espacios burocráticos de políticas para el desarrollo rural en Argentina. Reflexiones a partir de la Unidad para el Cambio Rural», en Pampa. Revista Interuniversitaria de Estudios Territoriales, en prensa.

O’Donnell, G. (1993). «Acerca del Estado, la democratización y algunos problemas conceptuales. Una perspectiva latinoamericana con referencias a países poscomunistas», en Desarrollo Económico $\mathrm{n}^{\circ} 130$, pp. 163-184.

O’Donnell, G. (2010), Democracia, agencia y estado. Teoría con intención comparativa. Buenos Aires: Prometeo.

O’Donnell, G; Iazzetta, O y Vargas Cullel, J. (Ed.) (2003), Democracia, desarrollo humano y ciudadanía. Reflexiones sobre la calidad de la democracia en América Latina. Homo Sapiens, Rosario. 
O`Donnell, G. (1978). «Apuntes para una teoría del Estado», en Revista Mexicana de Sociología, $\mathrm{n}^{\mathrm{o}} 4$, pp.1157-1199.

Olsen, J. (2005). «Maybe it is time to rediscover Bureacracy», en JPart, n 16, pp.1-42.

Olsen, J. (2007). «Ups and downs of the bureaucratic organization», en Documento de Trabajo, Arena.

Oszlak, O. (1984). Políticas públicas y regímenes políticos: reflexiones a partir de experiencias Latinoamericanas. Estudios CEDES, Buenos Aires.

Oszlak, O. (1997). «Estado y sociedad: nuevas reglas del juego», en Reforma y Democracia, CLAD, ${ }^{\circ}$ 9, Caracas, pp. 1-41.

Oszlak, O. (1999). «De menor a mejor, el desafío de la segunda reforma del Estado», en Revista Nueva Sociedad, no 160 , pp. 1-18.

Oszlak, O. (2003). «El mito del Estado mínimo: una década de reforma estatal en Argentina», en Revista Desarrollo Económico, vol. 42, n 168, 2003 pp.1-14.

Oszlak, O y O’Donnell, G. (1976). Estado y políticas estatales en América Latina. Hacia una estrategia de investigación, en Documento CEDES/GE CLACSO, nº 1 , Buenos Aires.

Portantiero, J. C. (1989). «La múltiple transformación del Estado latinoamericano», en Revista Nueva Sociedad, nº104, pp. 88-94.

Peters, G. (2005). «Gobernanza y Burocracia pública: ¿Nuevas formas de democracia o nuevas formas de control?», en Foro Internacional, n ${ }^{\circ}$, pp.585-598.

Prats, J. (2004). «De la burocracia al management y del management a la gobernanza», en Instituciones y Desarrollo, $\mathrm{n}^{\mathrm{o}} 3$, s/d.

Porras Martínez, J. (2001). «Policy network o red de políticas públicas: una introducción a su metodología de investigación», en Estudios Sociológicos XIX, nº 57, pp. 721-744.

Rosanvallon, P. (2007). La contrademocracia. La política en la era de la desconfianza. Manantial, Buenos Aires

San Martín Cantero, D. (2014), «Teoría fundamentada y Atlas.ti: Recursos metodológicos para la investigación educativa», en Revista Electrónica de Investigación Educativa, $\mathrm{n}^{\mathrm{o}} 1$.

Saz Carranza, Á y Serra, A. (2006). «La gestión de redes inter-organizativas desde el sector público: el caso de los servicios sociales en Barcelona», en Revista Territorios, $\mathrm{n}^{\circ}$ 15, $\mathrm{pp}$. 53-69.

Schmitter, P. (1992). «¿Continúa el siglo del corporativismo», en Schmitter, P y Lehmbruch, G. (Comp.). Neocorporativismo I: Más allá del Estado y el mercado. Alianza, México.

Souza, C. (2006). «Políticas Públicas: una revisão da literatura», en Sociologias, nº 16, pp.2045.

Subirats, J. (1989). Análisis de politicas públicas y eficacia de la Administración. Instituto Nacional de la Administración Pública, Madrid.

Thwaites Rey, M. (2008). «¿Qué Estado tras el experimento neoliberal?, en Revista del CLAD, Reforma y Democracia, $\mathrm{n}^{\circ}$ 41, pp 1-12

Weber, M. (1944). Economía y Sociedad. Esbozo para una Sociología Comprensiva.

Zurbriggen, C. (2011) «La utilidad del análisis de redes de políticas públicas», en Argumentos, año $24, n^{\circ} 66$, pp.181-208.

\section{Fuentes inéditas y digitales}

Ministerio de Agricultura, Ganadería y Pesca, decreto 1030/2014. Creación de la Secretaría de Agricultura Familiar. 
Ley de Reparación Histórica de la Agricultura Familiar para la construcción de una nueva ruralidad en Argentina. Número 27.118.

Ministerio de Agricultura, Ganadería y Pesca, resolución 571/2014. Creación del Consejo de la Agricultura Familiar, Indígena y Campesina.

Ministerio de Economía y Producción. Secretaria de Agricultura, Ganadería, Pesca y Alimentos, resolución 133/2006. Creación del Foro de Políticas Rurales.

Secretaria de Agricultura, Ganadería, Pesca y Alimentos, resolución 8/2008. Aprobación del Plan de Apoyo a Pequeños y Medianos Productores.

Secretaria de Agricultura, Ganadería, Pesca y Alimentos, resolución 255/2007. Creación del Registro Nacional de Agricultura Familiar y la Unidad de Registro Nacional de la Agricultura Familiar.

Secretaría de Coordinación y Monitoreo Institucional. Secretaria de Desarrollo Rural y Administración Federal de Ingresos Públicos, resolución conjunta 4263/2010, 9/2010 y 2880. Creación del Régimen de Monotributo Social.

Diario La Nación

Diario Tiempo Argentino

Diario Página 12

Biblioteca virtual PROINDER. 